\title{
Gold nanoparticles enhance microRNA 31 detection in colon cancer cells after inhibition with chlorogenic acid
}

\author{
ANA C. LUQUE-BADILLO ${ }^{1}$, GRISELDA HERNANDEZ-TAPIA ${ }^{1}$, DHAMAR A. RAMIREZ-CASTILLO ${ }^{1}$, \\ DIEGO ESPINOZA-SERRANO ${ }^{1}$, ALAN M. CORTES-LIMON ${ }^{1}$, JUAN P. CORTES-GALLARDO ${ }^{1}$, \\ DANIEL A. JACOBO-VELÁZQUEZ ${ }^{1}$, MARGARITA L. MARTINEZ-FIERRO ${ }^{2}$ and CLARA P. RIOS-IBARRA ${ }^{1}$ \\ ${ }^{1}$ School of Engineering and Sciences, Tecnologico de Monterrey, Campus Guadalajara, Jalisco 45138; \\ ${ }^{2}$ Molecular Medicine Laboratory, Academic Unit of Human Medicine and Health Sciences, \\ Universidad Autónoma de Zacatecas, Zacatecas 98040, Mexico
}

Received March 24, 2021; Accepted July 19, 2021

DOI: 10.3892/ol.2021.13003

\begin{abstract}
In the present study, the inhibitory effect of chlorogenic acid (CGA), a phenolic compound with potential antitumor effects, on circulating microRNA 31 (miR-31), was evaluated in RKO colon cancer cells. The capacity of gold nanoparticles (AuNPs) to enhance miR-31 quantification after treatment with CGA was assessed. RKO cells were treated with different concentrations of CGA for 24, 48 and $72 \mathrm{~h}$, after which AuNPs coupled to CD81 were added to the supernatants. Total RNA was extracted, and miR-31 was quantified by reverse transcription-quantitative PCR. The results revealed an $85 \%$ decrease in miR-31 level following treatment with $1,000 \mu \mathrm{M}$ CGA for $72 \mathrm{~h}$, and the highest capacity to detect miR-31 (after treatment and isolation with AuNPs + CD81) was observed at $24 \mathrm{~h}$. Furthermore, CGA decreased the expression of the miR-31 oncogene in an in vitro colon cancer model, and the use of AuNPs enhanced the levels of miRNA detection. The results suggest that miR-31 inhibition is one mechanism by which CGA decreases colon cancer cell proliferation. Moreover, AuNPs can increase the capacity of miR-31 quantification, representing a new strategy to develop non-invasive tools for the molecular diagnosis and monitoring of colon cancer.
\end{abstract}

\section{Introduction}

The World Health Organization estimated that 10 million individuals succumbed to cancer in 2020, of which colon cancer exhibited the third highest rate of incidence (1). There

Correspondence to: Dr Clara P. Rios-Ibarra, School of Engineering and Sciences, Tecnologico de Monterrey, Campus Guadalajara, Av. General Ramon Corona 2514, Col. Nuevo Mexico, Zapopan, Jalisco 45138, Mexico

E-mail: clara_rios_ibarra@yahoo.com.mx

Key words: microRNA 31, chlorogenic acid, gold nanoparticles, oncogene inhibitor, colon cancer are several methods for detecting colon cancer, such as colonoscopy, fecal occult blood tests (FOBT) and fecal DNA tests (2). However, it should be emphasized that FOBT has low specificity and sensitivity. A promising technique for the diagnosis of colon cancer is the detection of DNA in stool. However, there are certain limitations for the use of this technique, since both DNA from the patient and intestinal bacteria can be detected, the latter of which is more highly prevalent in the stool (3).

Colonoscopy is the most reliable method for the early detection of colon cancer and premalignant lesions. However, its invasive nature and high cost restrict its widespread application (4). Timely diagnosis of colon cancer and early treatment are two fundamental factors for the successful approach of patients with colon cancer (5). Furthermore, it is essential to evaluate the cancer biomarkers of patients during different pharmacological treatments, in order to identify the most appropriate therapy. During a retrospective study of a phase I trial, in which patients with advanced disease received at least two cycles of treatment with anti-programmed cell death protein 1/programmed cell death 1 ligand 1 , a decrease in the neutrophil-to-lymphocyte ratio was detected, and treatment was associated with prolonged progression-free survival (6).

MicroRNAs (miRNAs/miRs) are small, conserved, non-coding RNAs of 17-24 nucleotides, transcribed by RNA polymerase II (7). miRNAs can trigger post-transcriptional gene silencing by binding the $3^{\prime}$ untranslated region of target genes, rendering messenger RNA (mRNA) inaccessible, and thus inhibiting translation (8). During altered physiological processes, such as cancer, different cells can secrete miRNAs into the extracellular space, which are further transported in systemic circulation (9). These circulating miRNAs can be found in different tissues and biological fluids, including peripheral blood, saliva, follicular fluid, urine, breast milk and semen (10). The stability of extracellular miRNAs is the result of packaging into exosomes, extracellular vesicles released into biological fluids that act as carriers and prevent the RNase-associated degradation of nucleic acids (11). Exosomal miRNAs are known to be potential biomarkers for cancer screening, which may reduce the need for invasive techniques 
such as colonoscopy (12). miRNAs can also be used to predict chemotherapeutic efficiency; previously, miR-20a, -130 and -145 have been reported as novel predictive markers for FOLFOX regimen resistance in colorectal cancer (13). Furthermore, due to its upregulation in patients, miR-31 has been used for the diagnosis of colon cancer (14). miRNA detection is primarily based on reverse transcription-quantitative (RT-qPCR) and/or microarray analysis. However, since miRNAs are short sequences that can be difficult to isolate, these techniques may be of limited use in certain conditions, including paraffin embedded tissue. To overcome this problem, conventional quantification techniques, such as nanotechnology-based approaches, could be implemented to generate the most sensitive and stringent tests for miRNA detection (15). Metal nanoparticles, such as silver and gold nanoparticles (AuNPs), are of great interest in the medical field due to their properties and applications, especially as diagnostic and therapeutic tools (16). AuNPs are reliable fluorescence quenchers, and as such, enhance the sensitivity and selectivity of fluorescence-based approaches, including the detection of miRNAs in cancer cells, tissues and biological fluids (17). During tumor development, miRNAs can be secreted into the extracellular environment and encapsulated in exosomes; since exosomes can be detected by AuNPs coupled to CD81, a cell surface protein highly expressed in cellular proliferation and differentiation events, these miRNAs can serve as cancer biomarkers (18).

Chlorogenic acid (CGA) is a compound found in a variety of fruits and vegetables, including apples, pears and carrots. CGA is highly abundant in nature, and due to its high content in coffee beans, is the primary polyphenol consumed in various populations (19). CGA is also active against a wide range of microorganisms, including bacteria, viruses, yeasts, molds and amoebas (20). Likewise, the primary metabolite of CGA (dihydrocaffeic acid) is produced by the gut microbiota, possesses anticancer activity against colon cancer $(21,22)$.

Considering both the advantages of miRNAs for the diagnosis of several types of human cancer, and the inhibitory effects of CGA on oncogene expression, could highlight novel mechanisms of non-invasive molecular cancer diagnosis, resulting in the identification of adjuvant treatments for patients with colon cancer (23). The aim of the present study was to evaluate the antitumor potential of CGA, quantifying the suppression of miR-31 expression in an in vitro model of colon cancer. Furthermore, AuNPs were used to evaluate whether their use increased the detection of circulating miRNAs in the culture medium.

\section{Materials and methods}

Cell culture and CGA treatment. RKO human colon cancercells (ATCC; CRL-2577) were cultured in Advanced Dulbecco's Modified Eagle's Medium (ADMEM) supplemented with $10 \%$ fetal bovine serum (FBS), $1 \%$ penicillin-streptomycin (all Gibco; Thermo Fisher Scientific, Inc.) and 1\% L-glutamine (Sigma-Aldrich; Merck KGaA), in a humidified incubator at $37^{\circ} \mathrm{C}\left(5 \% \mathrm{CO}_{2}\right)$. For passage, the cells were washed with sterile $1 \mathrm{X}$ phosphate-buffered saline (PBS), and digested with trypsin (0.25\%)-EDTA solution (Gibco; Thermo Fisher
Scientific, Inc.) for $5-10 \mathrm{~min}$ at $37^{\circ} \mathrm{C}$. To inactivate the enzyme, an equal volume of medium supplemented with FBS was added to the trypsin/cell mixture, which was subsequently centrifuged at $300 \mathrm{x} \mathrm{g}$ for $5 \mathrm{~min}$ at room temperature. The supernatant was removed, and the cell pellet was resuspended in 2-4 ml culture medium. The cells were subcultured at a ratio of $1: 3$ to $1: 12$ and incubated at $37^{\circ} \mathrm{C}$ with $5 \% \mathrm{CO}_{2}$ until $80 \%$ confluent.

CGA treatment and viability assessment. To determine the effects of CGA on survival, cell cultures underwent a cell viability assay (Sigma-Aldrich; Merck $\mathrm{KGaA}$ ) following treatment with 250, 500, 750 and $1,000 \mu \mathrm{M}$ CGA for 24,48 and $72 \mathrm{~h}$. The viability assay was performed in triplicate using Alamar Blue (Invitrogen; Thermo Fisher Scientific, Inc.) with $4 \times 10^{4}$ RKO cells/well in a 96-well plate, with each well initially containing $200 \mu 1$ ADMEM; three cell-free wells served as the negative control. Following CGA treatment at the specified time and concentration, the medium was removed, and $200 \mu$ l Alamar Blue was added to each well. The plate was incubated until a color change was observed in cells without treatment, and the optical density (OD) was determined using a Multiskan Go microplate reader (Thermo Fisher Scientific, Inc.) at 570/600 $\mathrm{nm}$.

We selected $1,000 \mu \mathrm{M}$ CGA after the results of the viability assay with alamar blue. Subsequently, $1.2 \times 10^{5} \mathrm{RKO}$ cells were transferred to a 24-well plate and cultured in the presence of $1,000 \mu \mathrm{M}$ CGA. The cells were incubated for 24,48 and $72 \mathrm{~h}$, after which $300 \mu$ l supernatant was recovered from each well and stored at $-20^{\circ} \mathrm{C}$ until RNA isolation.

RNA isolation with AuNPs + CD81. Exosomal miR-31 quantification was conducted from a cell culture sample treated with $1,000 \mu \mathrm{M}$ CGA; prior to the extraction of miR-31, the aliquot of culture medium was treated with AuNPs coupled to CD81 (AuNPs + CD81). Briefly, miRNA was extracted from the supernatant (culture medium) of RKO cells. This medium was treated with different combinations of factors, following a $3 \times 2 \times 2$ mixed factorial design (in triplicate). Specifically, the three analyzed factors were as follows: incubation time (24, 48 and $72 \mathrm{~h}$ ), CGA (treated with $1,000 \mu \mathrm{M}$ or untreated) and AuNPs + CD81 (presence or absence).

For treatment with AuNPs + CD81, the Gold Conjugation Kit ( $40 \mathrm{~nm}, 20 \mathrm{OD}$; Abcam) was used according to the manufacturer's instructions. Firstly, $50 \mu \mathrm{l}$ of a mixture containing Gold Reaction Buffer, Gold Quencher, CD81 antibody $(0.02 \mathrm{mg} / \mathrm{ml})$ and lyophilized AuNPs was added to $300 \mu \mathrm{l}$ culture medium, the mix was incubated $10 \mathrm{~min}$ at room temperature.

For miRNA isolation, the mirVana ${ }^{\mathrm{TM}}$ miRNA Isolation kit (Ambion; Thermo Fisher Scientific, Inc.) was used, per the manufacturer's protocol. To homogenize the solution, miRNA Homogenate Additive was added (incubation $10 \mathrm{~min}$ at $4^{\circ} \mathrm{C}$ ), followed by acid-phenol-chloroform (5:1), $\mathrm{pH} 4.5$. The samples were later centrifuged at $25^{\circ} \mathrm{C}$ for $5 \mathrm{~min}$ at $10,000 \mathrm{x} \mathrm{g}$. The aqueous phase containing miRNAs was recovered and transferred to a new tube, leaving behind lipids, proteins, and salts. Subsequently, $100 \%$ ethanol was mixed with the aqueous solution, and filtered by passing the samples through filter cartridges (containing a glass-fiber filter which immobilizes the RNA; Ambion; Thermo Fisher Scientific, Inc.) and spinning 


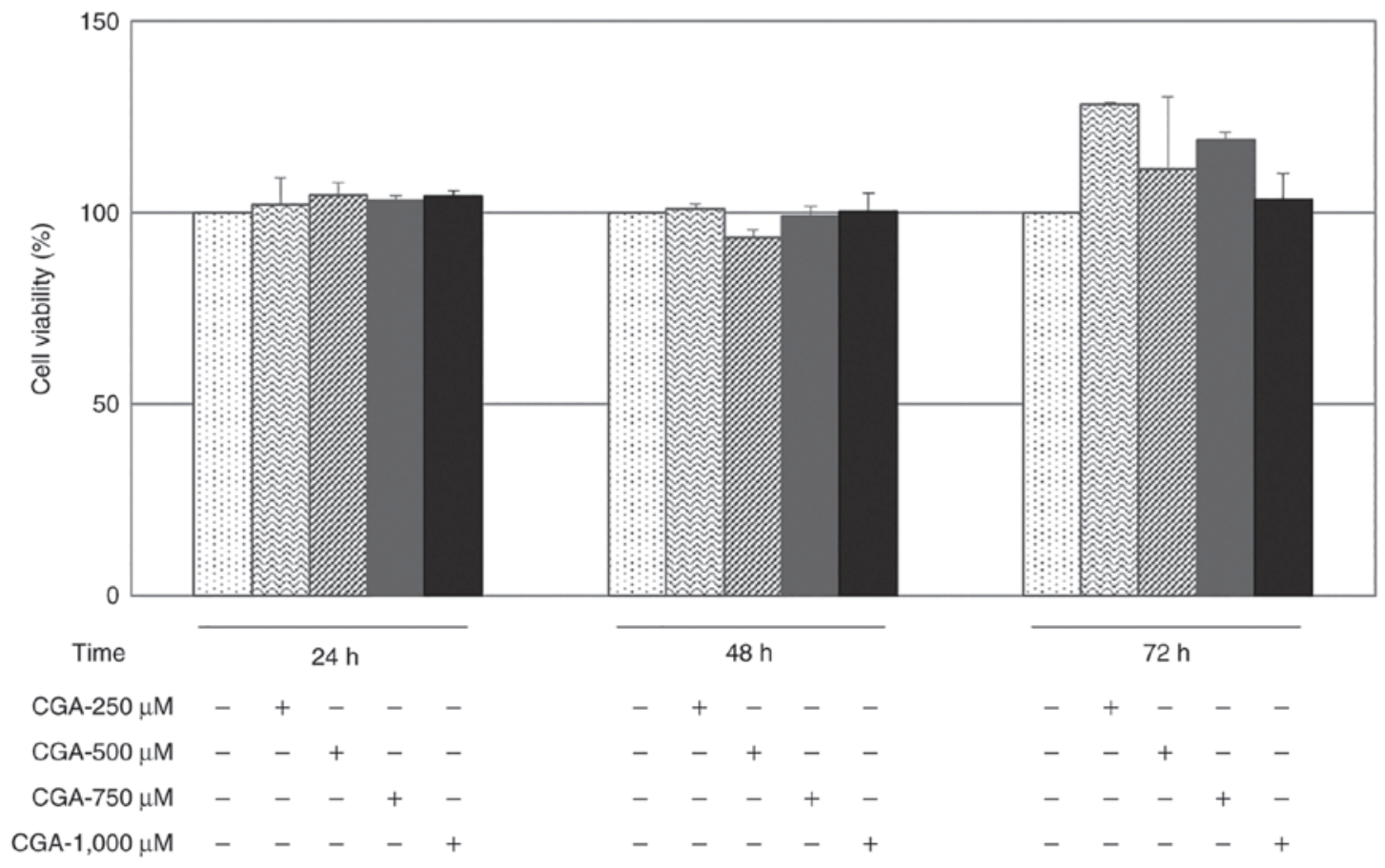

Figure 1. Viability of RKO colon cancer cells following treatment with CGA. RKO colon cancer cells were exposed to 250, 500, 750 and 1,000 $\mu$ M CGA for 24,48 and $72 \mathrm{~h}$ to evaluate the potential cytotoxicity of CGA. There was no statistically significant difference in viability following CGA treatment at any concentration for 24, 48 and $78 \mathrm{~h}$, compared with the negative control. (-), Untreated cells; (+), cells treated with CGA; CGA, chlorogenic acid.

at $10,000 \mathrm{x} \mathrm{g}$ for $15 \mathrm{sec}$ at room temperature. Washing solutions were added to the filter cartridges, and finally, miRNA was eluted with $100 \mu \mathrm{l}$ preheated elution solution $\left(95^{\circ} \mathrm{C}\right)$, and stored at $-20^{\circ} \mathrm{C}$.

$R T-q P C R$. RNA was reverse transcribed from the total RNA extracted using TaqMan Advanced miRNA Assays (Applied Biosystems; Thermo Fisher Scientific, Inc.) and a MyCycler $^{\mathrm{TM}} 1709713$ (Bio-Rad Laboratories, Inc.). The reaction conditions were as follows: $42^{\circ} \mathrm{C}$ for $15 \mathrm{~min}$ and $85^{\circ} \mathrm{C}$ for $5 \mathrm{~min}$. The amount of total cDNA obtained after RT was measured using a NanoDrop 2000c (NanoDrop Technologies; Thermo Fisher Scientific, Inc.). Then, qPCR was performed to quantify miR-31. Expression levels were normalized to that of miR-191, which is constitutively expressed. The primers used in both cases were 20X miR-Amp Primer Mix (A25576; Applied Biosystems; Thermo Fisher Scientific, Inc.) TaqMan fluorescent probes for miR-31 (ref. 477827_miR-31; Applied Biosystems) and miR191 (ref. 477952_mir191; Applied Biosystems) were used, as well as specific primers for both miR-31 and miR-191. The reaction was carried out using the StepOnePlus Real-Time PCR System (Applied Biosystems) with the following thermocycling conditions: $95^{\circ} \mathrm{C}$ for $20 \mathrm{sec}$, then 40 cycles of $95^{\circ} \mathrm{C}$ for $1 \mathrm{sec}$ and $60^{\circ} \mathrm{C}$ for $20 \mathrm{sec}$. The results were analyzed using the $2^{-\Delta \Delta \mathrm{Cq}}$ method (24). Each experiment was performed in triplicate and using untreated cells as a negative control.

Statistical analysis. The RT-qPCR results were evaluated using one-way ANOVA followed by Dunnett's post hoc test using SPSS for Windows, v.20 (IBM Corp.). Data are presented as the mean \pm SD. $P<0.05$ was considered to indicate a statistically significant difference.

\section{Results}

Viability of RKO cells treated with CGA. To assess viability, RKO cells were incubated for up to $72 \mathrm{~h}$ with 250, 500, 750 and 1,000 $\mu \mathrm{M}$ CGA. There were no cytotoxic effects of CGA on RKO cells at the evaluated concentrations at 24,48 or $72 \mathrm{~h}$ post-treatment (Fig. 1). Nevertheless, the highest concentration $(1,000 \mu \mathrm{M})$ was selected for subsequent experiments to obtain the most significant inhibitory effect, and following the information found in a previous study (25). The CGA did not show a cytotoxic effect on RKO at any of the assessed concentrations.

Evaluation of miR-31 levels following treatment with CGA. To evaluate whether $1,000 \mu \mathrm{M}$ CGA could modulate miR-31 expression in RKO cells, the miR-31 level was quantified from cell supernatants by RT-qPCR. miR-31 expression was downregulated at $24\left(\sim 97 \% ; \mathrm{P}=1.7 \times 10^{-5}\right), 48(\sim 75 \% ; \mathrm{P}=0.002)$ and $72 \mathrm{~h}\left(\sim 85 \% ; \mathrm{P}=3.08 \times 10^{-4}\right)$ post-treatment with CGA (Fig. 2), compared with the untreated controls at the same timepoints. Therefore, 1,000 $\mu \mathrm{M}$ CGA can reduce the expression levels of the oncogene, miR-31.

miR-31 levels following treatment with CGA and isolation with $A u N P s+C D 81$. RKO cells were harvested at 24, 48 or $72 \mathrm{~h}$ for miRNA isolation in the presence or absence of AuNPs + CD81. This experiment aimed to evaluate whether the use of nanoparticles allowed the detection of higher miR-31 levels after treatment with CGA, compared with the isolation of miRNAs without AuNPs + CD81. The greatest effect was observed at $24 \mathrm{~h}\left(\sim 55 \%, \mathrm{P}=7.3 \times 10^{-5}\right)$ without AuNPs + CD81 (Fig. 3). In Fig. 1 and 2, the inhibitory effect of CGA on miR-31 can be observed; however, the use of AuNPs optimized the 


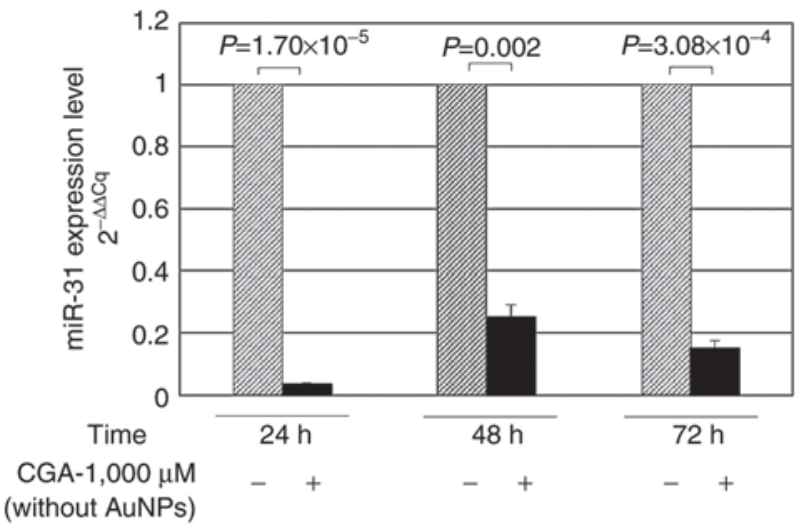

Figure 2. Quantification of miR-31 isolated from the supernatants of RKO colon cancer cells treated with CGA, without AuNPs. Cells were cultured in 24-well plates and treated with 1,000 $\mu \mathrm{M}$ CGA. Total RNA was isolated, and miR-31 was quantified at 24,48 and $72 \mathrm{~h}$ by reverse transcription-quantitative PCR. miR-31 quantification was significantly higher in cells that were not treated with CGA, demonstrating the antitumoral properties of CGA by the reduction of the tumoral marker miR-31. (-), Untreated cells; (+), cells treated with 1,000 $\mu$ M CGA. miR, microRNA; CGA, chlorogenic acid; AuNPs, gold nanoparticles.

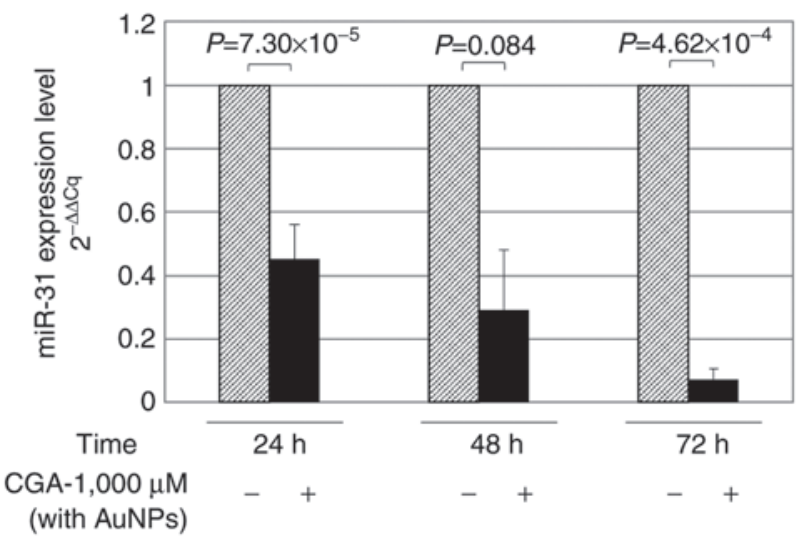

Figure 3. Quantification of miR-31 isolated from the supernatants of RKO colon cancer cells treated with CGA, with AuNPs. Cells were cultured in 24-well plates and treated with 1,000 $\mu \mathrm{M}$ CGA. Total RNA, and miRNAs encapsulated in exosomes coupled with AuNPs + CD81, were isolated. miR-31 was quantified at 24,48 , and $72 \mathrm{~h}$ by reverse transcription-quantitative PCR. Decreased concentrations of miR-31 were found when treated with CGA for different times of exposure. (-), Untreated cells; (+) cells treated with CGA 1,000 $\mu \mathrm{M}$ and AuNPs. miR, microRNA; CGA, chlorogenic acid; AuNPs, gold nanoparticles.

capacity of the quantification method. Consequently, when compared with isolation without AuNPs, a higher level of miR-31 was quantified at $24 \mathrm{~h}$ when AuNPs were used to optimize RT-qPCR detection, (in both cases the cells were treated with CGA $1,000 \mu \mathrm{M})\left(\mathrm{P}=3.06 \times 10^{-4}\right.$; Fig 4). According to the results of the present study, this strategy could be implemented in patients with colon cancer to isolate exosomes using AuNPs + CD81 and optimize the quantification of miRNAs derived from serum/plasma.

\section{Discussion}

The aim of the present study was to evaluate the antitumor potential of CGA by quantifying the suppression of the

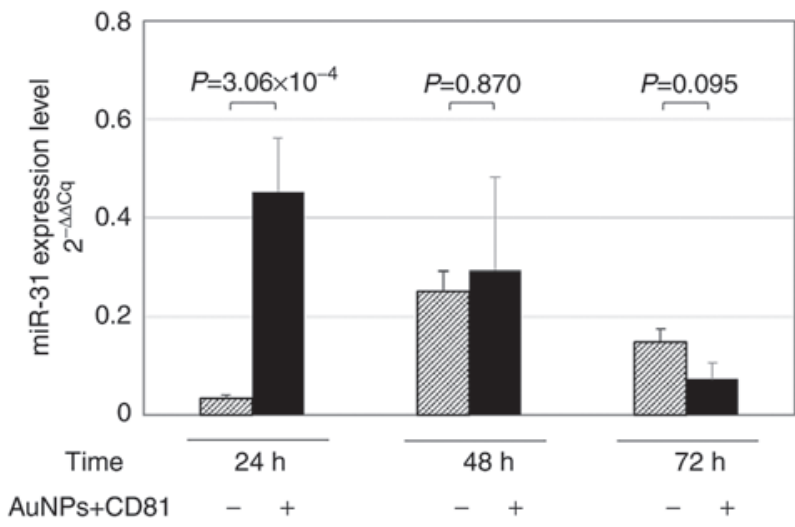

Figure 4. Comparison between miR-31 levels with and without AuNPs. AuNPs + CD81 increased the sensitivity of miR-31 quantification $24 \mathrm{~h}$ after treatment with $1,000 \mu \mathrm{M}$ CGA, since a higher concentration of miR-31 was detected when using AuNP's for the isolation of miRNAs. (-) miRNA extraction without AuNPs + CD81; (+) extraction with AuNPs + CD81; miR, microRNA; CGA, chlorogenic acid; AuNPs, gold nanoparticles.

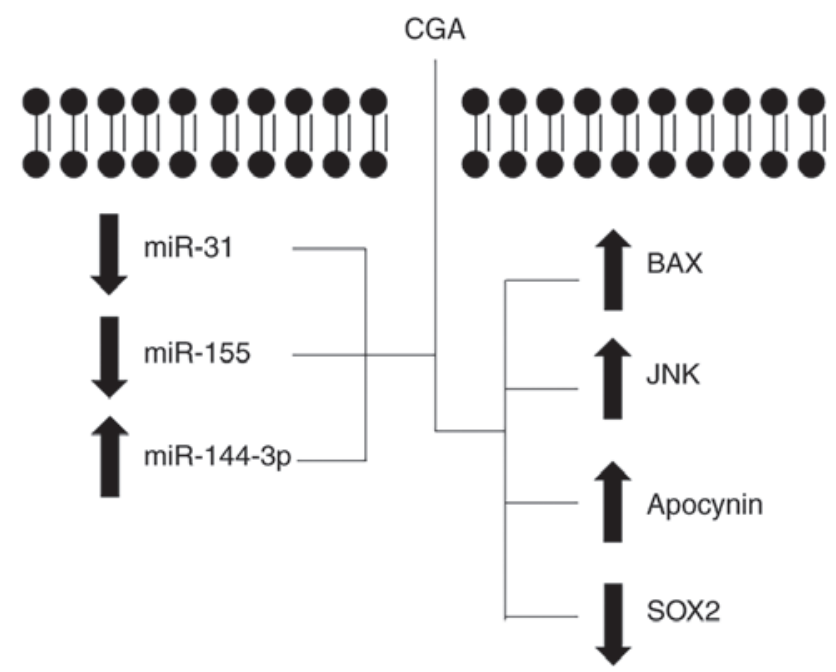

Figure 5. Genes regulated by CGA. In the present study, miR-31 was quantified after treatment with CGA, which modifies its expression levels, as well as that of other biomarkers. miR-31 is an oncogene. It has been reported that other oncological biomarkers can be regulated through CGA: miR-155 modulates apoptosis. miR-144-3p is a tumor suppressor. BAX is an inducer of apoptosis. JNK participates in the programmed cell death pathway. Apocynin is a NADPH oxidase inhibitor. SOX2 participates in several stages of embryonic development. miR, microRNA; CGA, chlorogenic acid.

miR-31 in an in vitro model of colon cancer. Furthermore, the potential use of AuNPs to increase the levels of circulating miRNAs in the culture medium (and thus enhance their detection) was also assessed. AuNPs + CD81 were used to isolate miRNAs encapsulated in exosomes from the culture medium of RKO colon cancer cells, which were treated with $1,000 \mu \mathrm{M}$ CGA for 24,48 and $72 \mathrm{~h}$. The RT-qPCR results showed that CGA significantly inhibited miR-31 expression at $24(\sim 97 \%), 48(\sim 75 \%$,$) and 72 \mathrm{~h}(\sim 85 \%)$ compared with negative controls. Numerous studies have reported that CGA serves important therapeutic roles, including as an antioxidant, antibacterial, hepatoprotective, cardioprotective, anti-inflammatory, antipyretic, neuroprotective, anti-obesity, antiviral, anti-microbial and anti-hypertensive agent, as 
well as a free radical scavenger, central nervous system stimulator and oncogene inhibitor (20-22,26-28). CGA was also found to regulate the expression of apoptosis-related genes in lung and colon cancer cell lines $(25,29)$, the latter of which appear to be especially affected by CGA. For example, Hou et al (30) showed that CGA has several effects on colon cancer cells (HCT116 and HT29), including S-phase arrest, extracellular signal-related kinase inactivation, induced reactive oxygen species and a decrease in cell viability. These results suggest CGA as a potential treatment for colorectal cancer (30).

miRNAs regulate $\sim 30 \%$ of human genes; they act as oncogenic and tumor suppressor genes, and as such, are frequently dysregulated in cancer (31). The oncomiR-31 inhibits the translation of RAS P21 protein activator 1, an inhibitor of KRAS protooncogene, thus stimulating the transcription of the KRAS oncogene, which promotes cell cycle progression in colon cancer cells (32). According to previous research, miR-31, and other miRNAs such as miR155 (33) and miR144-3p (34), are modulated by CGA (Fig. 5). Hence, they have great potential as biomarkers for colon cancer diagnosis, and in disease monitoring during treatment. However, as short-sequence molecules, miRNAs are difficult to isolate from some biological samples (such as feces). Therefore, in conventional quantification techniques, nanotechnology-based approaches may be used to develop the most sensitive and stringent methods for miRNA detection (16).

To determine whether the addition of AuNPs increased the sensitivity of miRNA detection, the present study aimed to quantify miR-31 expression after treatment with $1,000 \mu \mathrm{M}$ CGA $(24,48$ and $72 \mathrm{~h})$, and to isolate total RNA using AuNPs + CD81. The most significant increase in miR-31 quantification was observed at $24 \mathrm{~h}$; this maximum inhibition may be attributed to the antioxidant effect of CGA during the earliest exposure time (29). AuNPs have a variety of properties and uses, making them amenable to a variety of detection modalities and techniques (35). As supported by the present study results, a novel strategy can be proposed to quantify miR-31 expression using AuNPs; miR-31 expression can serve as an effective, non-invasive molecular diagnostic and monitoring tool for colon cancer. The efficacy of this strategy as an alternative non-invasive diagnostic method could be validated in fecal samples by extracting and quantifying miRNAs encapsulated in exosomes that were previously isolated with nanoparticles (36). In addition, CGA significantly decreased miR-31 expression at 24, 48 and $72 \mathrm{~h}$, which may be explained by one of the antitumor mechanisms of CGA in colon cancer. Moreover, the present results indicate that AuNPs may optimize the miRNA isolation method. However, additional studies are necessary to validate this approach, using biological samples from patients with colon cancer to establish its diagnostic potential in disease.

\section{Acknowledgements}

To authors of the present study would like to thank Dr Mauricio Salinas-Santander (School of Medicine, Universidad Autonoma de Coahuila) for their help formatting the figures.

\section{Funding}

The present study was supported by the State Council of Science and Technology (COECyTJAL, grant no. 4673-2016 to Clara Patricia Rios-Ibarra).

\section{Availability of data and materials}

The datasets used and/or analyzed during the current study are available from the corresponding author upon reasonable request.

\section{Authors' contributions}

CPRI designed the present study. CPRI, ACLB, DARC, GHT, AMCL, DES and JPCG performed the experiments and acquired the data. CPRI and MLMF performed data curation. CPRI, MLMF and DAJV analyzed the results and interpretated the data. CPRI, DAJV and MLMF provided resources. All authors were involved in the preparation of the original drafted manuscript, which was reviewed and edited by CPRI, DAJV and MLMF. CPRI, DAJV and MLMF supervised the study. CPRI and ACLB confirmed the authenticity of all the raw data. All authors have read and approved the final manuscript.

\section{Ethics approval and consent to participate}

Not applicable.

\section{Patient consent for publication}

Not applicable.

\section{Competing interests}

The authors declare that they have no competing interests.

\section{References}

1. Cancer. Available online: https://www.who.int/news-room/factsheets/detail/cancer.

2. Hamzehzadeh L, Yousefi M and Ghaffari SH: Colorectal cancer screening: A comprehensive review to recent non-invasive methods. Int J Hematol Oncol Stem Cell Res 11: 250-261, 2017.

3. Zarkavelis G, Boussios S, Papadaki A, Katsanos KH, Christodoulou DK and Pentheroudakis G: Current and future biomarkers in colorectal cancer. Ann Gastroenterol 30: 613-621, 2017.

4. Lin J, Chuang CC and Zuo L: Potential roles of microRNAs and ROS in colorectal cancer: Diagnostic biomarkers and therapeutic targets. Oncotarget 8: 17328-17346, 2017.

5. Mohammadi R, Ansari Chaharsoghi M, Khorvash F, Khorvash F, Kaleidari B, Sanei MH, Ahangarkani F, Abtahian Z, Meis JF and Badali H: An unusual case of gastrointestinal basidiobolomycosis mimicking colon cancer; literature and review. J Mycol Med 29: 75-79, 2019

6. Moschetta M, Uccello M, Kasenda B, Mak G, McClelland A, Boussios S, Forster M and Arkenau HT: Dynamics of neutrophils-to-lymphocyte ratio predict outcomes of PD-1/PD-L1 blockade. Biomed Res Int 2017: 1506824, 2017.

7. Saliminejad K, Khorram Khorshid HR, Soleymani Fard S and Ghaffari SH: An overview of microRNAs: Biology, functions, therapeutics, and analysis methods. J Cell Physiol 234: 5451-5465, 2019

8. Yao P, Wu J, Lindner D and Fox PL: Interplay between miR-574-3p and hnRNP L regulates VEGFA mRNA translation and tumorigenesis. Nucleic Acids Res 45: 7950-7964, 2017. 
9. Zhang YH, Jin M, Li J and Kong X: Identifying circulating miRNA biomarkers for early diagnosis and monitoring of lung cancer. Biochim Biophys Acta Mol Basis Dis 1866: 165847, 2020.

10. Wang H, Peng R, Wang J, Qin Z and Xue L: Circulating microRNAs as potential cancer biomarkers: The advantage and disadvantage. Clinical Epigenetics 10: 59, 2018.

11. Ingenito F, Roscigno G, Affinito A, Nuzzo S, Scognamiglio I, Quintavalle C and Condorelli G: The role of Exo-miRNAs in cancer: A focus on therapeutic and diagnostic applications. Int J Mol Sci 20: 4687, 2019.

12. Tinmouth J, Kennedy EB, Baron D, Burke M, Feinberg S, Gould M, Baxter N and Lewis N: Colonoscopy quality assurance in ontario: Systematic review and clinical practice guideline. Can J Gastroenterol Hepatol 28: 251-274, 2014.

13. Boussios S, Ozturk MA, Moschetta M, Karathanasi A Zakynthinakis-Kyriakou N, Katsanos KH, Christodoulou DK and Pavlidis N: The developing story of predictive biomarkers in colorectal cancer. J Pers Med 9: 12, 2019.

14. Wang Y, Chen Z and Chen W: Novel circulating microRNAs expression profile in colon cancer: A pilot study. Eur J Med Res 22: 51,2017.

15. Aldewachi H, Chalati T, Woodroofe MN, Bricklebank N, Sharrack B and Gardiner P: Gold nanoparticle-based colorimetric biosensors. Nanoscale 10: 18-33, 2017

16. Chaudhary V, Jangra S and Yadav NR: Nanotechnology based approaches for detection and delivery of microRNA in healthcare and crop protection. J Nanobiotechnol 16: 40, 2018.

17. Singh H, Du J, Singh P and Yi TH: Ecofriendly synthesis of silver and gold nanoparticles by Euphrasia officinalis leaf extract and its biomedical applications. Artif Cells Nanomed Biotechnol 46: 1163-1170, 2018.

18. Klymiuk MC, Balz N, Elashry MI, Heimann M, Wenisch S and Arnhold S: Exosomes isolation and identification from equine mesenchymal stem cells. BMC Vet Res 15: 42, 2019.

19. Loader TB, Taylor CG, Zahradka P and Jones PJH: Chlorogenic acid from coffee beans: Evaluating the evidence for a blood pressure-regulating health claim. Nutr Rev 75: 114-133, 2017.

20. Santana-Gálvez J,Cisneros-Zevallos L and Jacobo-Velázquez DA: Chlorogenic acid: Recent advances on its dual role as a food additive and a nutraceutical against metabolic syndrome. Molecules 22: 358, 2017.

21. Santana-Gálvez J, Villela-Castrejón J, Serna-Saldívar SO, Cisneros-Zevallos L and Jacobo-Velázquez DA: Synergistic combinations of curcumin, sulforaphane, and dihydrocaffeic acid against human colon cancer cells. Int J Mol Sci 21: 3108, 2020.

22. Santana-Gálvez J, Castrejón JV, Serna-Saldívar SO and Jacobo-Velázquez DA: Anticancer potential of dihydrocaffeic acid: A chlorogenic acid metabolite. CyTA J Food 18: 245-248, 2020.

23. Cekaite L, Eide PW, Lind GE, Skotheim RI and Lothe RA: MicroRNAs as growth regulators, their function and biomarker status in colorectal cancer. Oncotarget 7: 6476-6505, 2015.

24. Livak KJ and Schmittgen TD: Analysis of relative gene expression data using real-time quantitative PCR and the 2(-Delta Delta C(T)) Method. Methods 25: 402-408, 2001
25. Sadeghi Ekbatan S, Li XQ, Ghorbani M, Azadi B and Kubow S: Chlorogenic acid and its microbial metabolites exert anti-proliferative effects, S-phase cell-cycle arrest and apoptosis in human colon cancer Caco-2 cells. Int J Mol Sci 19: 723, 2018.

26. Tajik N, Tajik M, Mack I and Enck P: The potential effects of chlorogenic acid, the main phenolic components in coffee, on health: A comprehensive review of the literature. Eur J Nutr 56: 2215-2244, 2017.

27. Naveed M, Hejazi V, Abbas M, Kamboh AA, Khan GJ, Shumzaid M, Ahmad F, Babazadeh D, FangFang X, Modarresi-Ghazani F, et al: Chlorogenic acid (CGA): A pharmacological review and call for further research. Biomed Pharmacother 97: 67-74, 2018.

28. Wang X, Liu J, Xie Z, Rao J, Xu G, Huang K, Li W and Yin Z: Chlorogenic acid inhibits proliferation and induces apoptosis in A498 human kidney cancer cells via inactivating PI3K/Akt/mTOR signalling pathway. J Pharm Pharmacol 71: 1100-1109, 2019

29. Yamagata K, Izawa Y, Onodera D and Tagami M: Chlorogenic acid regulates apoptosis and stem cell marker-related gene expression in A549 human lung cancer cells. Mol Cell Biochem 441: 9-19, 2018.

30. Hou N, Liu N, Han J, Yan Y and Li J: Chlorogenic acid induces reactive oxygen species generation and inhibits the viability of human colon cancer cells. Anticancer Drugs 28: 59-65, 2017.

31. Si W, Shen J, Zheng H and Fan W: The role and mechanisms of action of microRNAs in cancer drug resistance. Clin Epigenetics 11: 25, 2019.

32. Strubberg AM and Madison BB: MicroRNAs in the etiology of colorectal cancer: Pathways and clinical implications. Dis Model Mech 10: 197-214, 2017.

33. Zeng J, Zhang D, Wan X, Bai Y, Yuan C, Wang T, Yuan D, Zhang $\mathrm{C}$ and Liu C: Chlorogenic acid suppresses miR-155 and ameliorates Ulcerative colitis through the NF- $\mathrm{KB} / \mathrm{NLRP} 3$ inflammasome pathway. Mol Nutr Food Res 64: e2000452, 2020.

34. Romualdo GR, Prata GB, da Silva TC, Evangelista AF, Reis RM, Vinken M, Moreno FS, Cogliati B and Barbisan LF: The combination of coffee compounds attenuates early fibrosis-associated hepatocarcinogenesis in mice: Involvement of miRNA profile modulation. J Nutr Biochem 85: 108479-108479, 2020

35. Coutinho C and Somoza Á: MicroRNA sensors based on gold nanoparticles. Anal Bioanal Chem 411: 1807-1824, 2019.

36. Duran-Sanchon S, Moreno L, Augé JM, Serra-Burriel M, Cuatrecasas M, Moreira L, Martín A, Serradesanferm A, Pozo À, Costa R, et al: Identification and validation of MicroRNA profiles in fecal samples for detection of colorectal cancer. Gastroenterology 158: 947-957.e4, 2020.

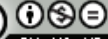

This work is licensed under a Creative Commons Attribution-NonCommercial-NoDerivatives 4.0 International (CC BY-NC-ND 4.0) License. 